\title{
Variation of Marginal Mandibular Nerve in a Caucasian Male Cadaver: A Study Using the Anatomage Table
}

\author{
Paschalis Strantzias ${ }^{1}$, Anna Botou ${ }^{2}$, Arezina Manoli ${ }^{3}$, Panagiotis N. Skandalakis ${ }^{4}$, Dimitrios Filippou ${ }^{4}$ \\ 1. Oral Medicine, Medical School of National and Kapodistrian University of Athens, Athens, GRC 2. Ophthalmology, \\ Medical School of National and Kapodistrian University of Athens, Athens, GRC 3. Otolaryngology, Medical School of \\ National and Kapodistrian University of Athens, Athens, GRC 4. Surgery, Medical School of National and Kapodistrian \\ University of Athens, Athens, GRC
}

Corresponding author: Paschalis Strantzias, pstrantzias@gmail.com

\begin{abstract}
Anatomage (Anatomage, Inc., San Jose, CA) is a modern method for studying anatomy. It is a state-of-theart method used for the representation of the structure of the human body. In our study, we examined the seventh cranial nerve of a male Caucasian cadaver using an Anatomage Table in the Anatomy Department of the School of Medicine, National and Kapodistrian University, Athens, Greece. After exiting the skull from the stylomastoid foramen, the facial nerve divided into the temporofacial and cervicofacial main branches. The cervicofacial branch divided into its own branches, including the marginal mandibular nerve (MMN), which ran within the investing (superficial) layer of the deep cervical fascia. We found a variation of the course of the marginal mandibular branch of the facial nerve. In the area of the lower border of the mandible, where the MMN actually crossed the facial artery and vein, it appeared to run deeper than both of those vessels, rather than running superficially. This seemed to be a rare variation of the location of the MMN relative to the facial vessels, which suggested that extra care is essential in surgical approaches within this area.
\end{abstract}

Categories: Other, Anatomy

Keywords: marginal mandibular nerve, anatomage, variation

\section{Introduction}

The anatomy of the human body is a cornerstone of modern medicine. Cadaver dissection has been the exclusive method of studying anatomy for centuries since Vesalius founded modern human anatomy. Complementary atlases of anatomy have always been fundamental to the study of the human body. At first, we generally relied on artists' drawings. Since then, we have gone through modern color graphics to real pictures taken of cadaver dissections. Such dissections have been the most common method used for educational purposes. However, there are several limitations to this approach. Running an anatomy lab is

Received 10/28/2019 Review began 10/30/2019 Review ended 11/09/2019 Published 11/16/2019

\section{() Copyright 2019}

Strantzias et al. This is an open access article distributed under the terms of the Creative Commons Attribution License CC-BY 3.0., which permits unrestricted use, distribution, and reproduction in any medium, provided the original author and source are credited. expensive and time-consuming. Its maintenance and personnel costs are too high, especially considering the constant need for cadaver supply, processing, and conservation. Unfortunately, when performing human cadaver dissection, there is no "undo" or "redo" option. Once a mistake is made and the tissue is inappropriately dissected, there is no going back until the next specimen is available. On the other hand, an increase in the number of students has created a great demand for specimens for training. It is a common practice for an instructor to perform manipulations and dissections while the students watch. Additionally, a cadaver's structures are fragile and affected by preservative chemicals. When examining a cadaver, visibility is limited to the exposed area of the tissue. In addition, the color and consistency of tissues and organs are quite different in a dead body. Furthermore, rotating a cadaver is not an easy option, meaning usually students can view only a part of the organ or anatomical system being examined. Most of these problems have been solved by the digitizing of human anatomy [1].

The Anatomage method has made great contributions in the attempt to visualize human anatomy. It is based on the concept of a virtual dissection table, reproducing a real cadaver bed and demonstrating real patient data on a real-size scale. It uses the same technology as the CT and MRI. Anatomage presents 3D reconstructions of the human body by combining data of the Visible Korean Project and the Visible Human Project, thus representing a quite accurate digital visualization of human anatomy. These 3D reconstructions can be dissected for internal inspection, and then subsequently segmented and annotated. This creates a safe working environment, free of any chemicals or hazardous materials that might harm students and other personnel during cadaver dissection [2].

In the Visible Human Project, researchers compiled data from MRI, CT, and anatomic images of a 38-yearold (at the time of death) male cadaver. The cadaver underwent CT scanning at $1 \mathrm{~mm}$ intervals through the head and neck; $3 \mathrm{~mm}$ intervals through the thorax, abdomen, and pelvis; $5 \mathrm{~mm}$ intervals through the lower extremities and, several months later, at $1 \mathrm{~mm}$ intervals through the entire body. The cadaver was then cut using a cryomacrotome at $1 \mathrm{~mm}$ intervals, and the slices were photographed with a digital camera. 


\section{Cureus}

Cryosections and CT scans were combined with these photos of the slices. The same procedure was performed with the MRI. As part of the same Visible Human Project, the same procedure was carried out with a female cadaver, with anatomical images taken at $0.33 \mathrm{~mm}$ intervals [3,4].

In the Visible Korean Project, a Korean male cadaver was chosen without any preservative procedure. The cadaver underwent MRI and CT scanning at $1 \mathrm{~mm}$ intervals. It was then frozen in a deep freezer and serially sectioned at $0.2 \mathrm{~mm}$ intervals using a cryomacrotome. Each sectioned surface was photographed with a digital camera, and 11 anatomical organs were segmented to produce segmented images. The anatomical and segmented images were perfused and reconstructed to produce 3D images $[5,6]$.

\section{Case Presentation}

We studied a Caucasian male specimen of the Anatomage Table's database (Anatomage Table 5) in the Anatomy Department of the Medical School of the National and Kapodistrian University of Athens. We discovered that the marginal mandibular nerve (MMN) appears as a single branch on both (left and right) sides. After its emergence from the cervicofacial division within the parotid gland, it exited the gland and ran above the lower border of the mandible at a maximum distance of $14.2 \mathrm{~mm}$ on the left and $12.8 \mathrm{~mm}$ on the right side.

We noticed an extremely rare variation in the course of the MMN and its location relative to the facial vessels. It was found deeper (medially) than the facial artery and vein instead of running superficially when crossing them, near the lower border of the mandible, still within the investing layer of the deep cervical fascia on both the right and left sides (Figures 1,2,3).

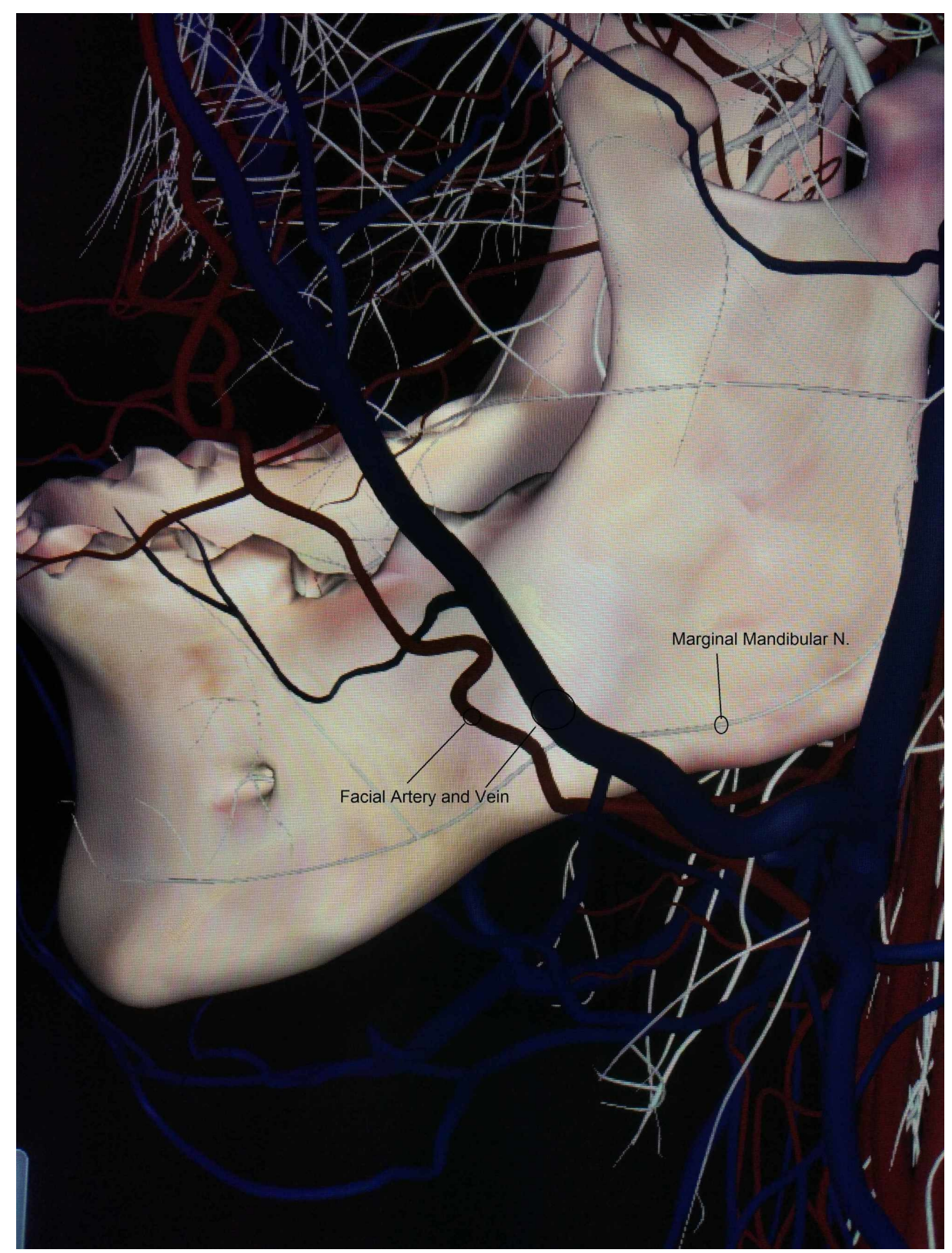




\section{Cureus}

FIGURE 1: Lateral view of the single branch of the left marginal mandibular nerve, which runs deeper than the facial artery and vein

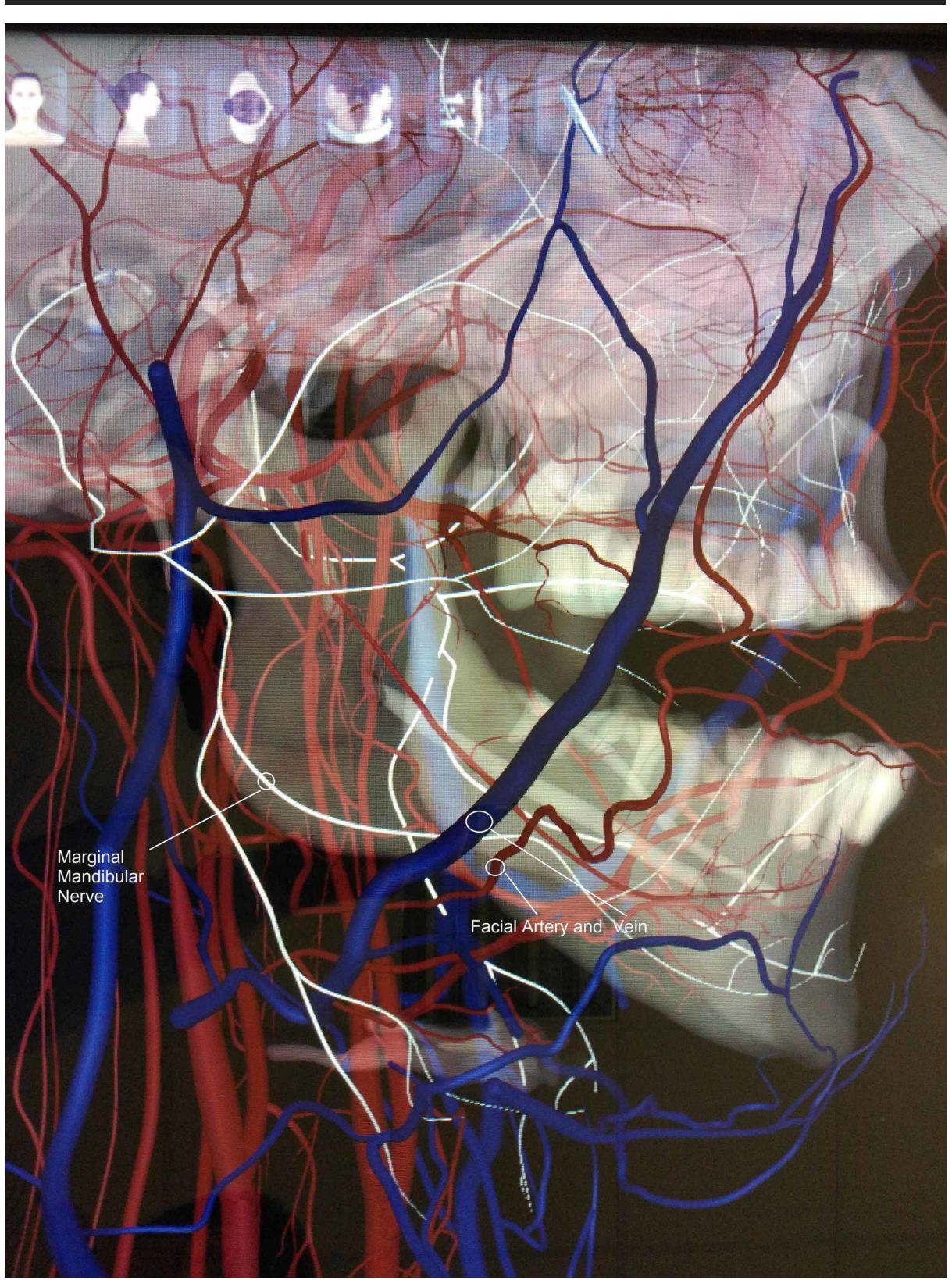

FIGURE 2: Lateral view of the single branch of the right marginal mandibular nerve, which runs deeper than the facial artery and vein 


\section{Cureus}

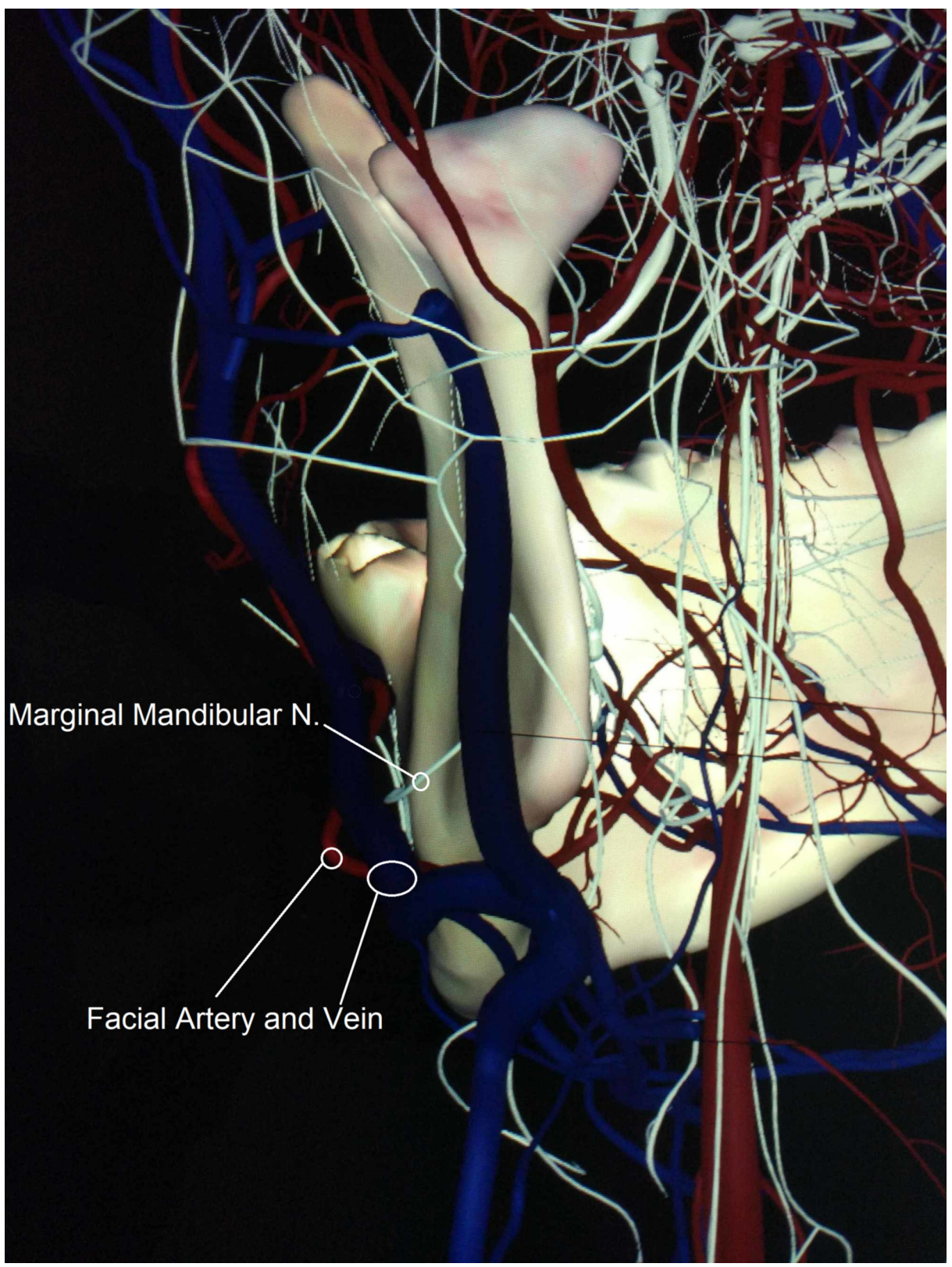

FIGURE 3: Retro-lateral view of the left marginal mandibular nerve, indicating a single branch that runs between facial vessels and the mandible

\section{Discussion}

The facial nerve is the seventh cranial nerve. It controls the facial muscles, gives sensory supply to the anterior two-thirds of the tongue and secretomotor supply to the submandibular, sublingual, and lacrimal glands. After its intracranial course, it exits the skull at the stylomastoid foramen. It then feeds into the posterior auricular branch and the supply branches for the posterior belly of the digastric muscle and the stylohyoid muscle. It then enters the parotid gland. After a short run in the gland, the main trunk splits into two main divisions: the temporofacial and the cervicofacial. These form the parotid plexus, which splits into five main branches: temporal, zygomatic, buccal, marginal mandibular, and cervical.

The marginal mandibular branch of the facial nerve supplies the muscles of the lower lip. It emerges from the inferior-anterior border of the parotid gland into the neck, where it lies deep to the platysma, within or just deep to the investing (superficial) layer of the deep cervical fascia. It then runs, in most cases, superficially to the facial artery and vein near the inferior border of the mandible [7]. According to Gray's Anatomy, the marginal mandibular branch passes below the lower border of the mandible in $20-50 \%$ of the cases, at a maximum distance of $1.2 \mathrm{~cm}$ [8]. In 1962, Dingman et al. stated that in $81 \%$ of specimens, the marginal mandibular branch posterior to the facial vessels passed above the inferior border of the mandible, and in 
the other $19 \%$ of the cases, it ran at a maximum of $1 \mathrm{~cm}$ below the inferior border; however, once it was found above the facial artery, it never curved below the mandible [9]. In 2010, Batra et al. found the marginal mandibular branch traversing along the mandible in $52 \%$ of the cases, below it in $32 \%$ and above it in $16 \%$ of the cases. When it was below the mandible, the distance was measured between 1.1 and $1.6 \mathrm{~cm} \mathrm{[10].}$ According to Woltmann et al., in $57.7 \%$ of the cases, the nerve passed superior to the inferior border of the mandible [11]. Saylam et al. found that the mandibular branch ran above the inferior border of the mandible in $74 \%$ of the cases [12]. Rödel and Lang described that in $66 \%$ of the cases, the branch ran below the lower margin of the mandible at a maximum of $1.4 \mathrm{~cm}$ [13]. Hwang et al. stated that the average distance between the lowest point of the mandibular branch and the inferior border of the mandible was $5.36 \mathrm{~mm}$ at the facial artery point [14].

The marginal mandibular branch of the facial nerve was found by Wang et al. to be a single branch in $32 \%$ of the cases and as two or more branches in $68 \%$ of the cases [15]. In another study, it was one branch in $28 \%$ of the cases, two branches in $52 \%$ of the cases, three in $18 \%$ of the cases, and four in $2 \%$ of the cases [16]. According to Dingman et al., there was a single branch in $21 \%$, two branches in $67 \%$, three branches in $9 \%$, and four major branches in $3 \%$ of specimens. However, most researchers agree that the marginal mandibular branch of the facial nerve crosses the superficial surface of the facial vessels in $100 \%$ of specimens [9]. In 2012, Balagopal et al. found just one division of MMN in approximately $80 \%$ of the patients who underwent neck dissection, two branches in $13 \%$, and three or more branches in $7 \%$. In most of the patients with one branch (60\%), it was found crossing the facial artery inferior to the lower border of the mandible. In patients with more than one branch, there was a wide variation in the course of the branches in relation to the lower border of the mandible in crossing the facial artery. They also determined that the mean distance of the branches of the MMN from the lower border of the mandible crossing the facial artery was $1.73 \mathrm{~mm}$ below it [17].

These wide measurements among different studies show that there is a gross variation in the course of the MMN, which increases when the neck of the patient is extended and rotated to the contralateral side due to the extension of the neck and traction of the tissue. Hwang's findings of the border-nerve distance suggest that the position of the MMN varies depending on the neck position [14,18].

On the other hand, there are differences between neck dissections performed on preserved cadavers and those performed on live patients. In 2004, Touré et al. stated that the MMN ran laterally to the vessel bundle in 51 out of 54 cases, and it was medially to the facial artery but laterally to the vein in two cases and laterally to the artery and medially to the vein in one case [19]. In 2018, Touré et al. dissected 62 half-heads from cadavers and discovered that the MMN was more consistently lateral to the facial vein than to the facial artery [20].

\section{Conclusions}

These findings corroborate that the male Caucasian cadaveric specimen of the Anatomage Table represents a rare variation of the position of the MMN in the area of the mandible when crossing the facial artery and vein near the lower border of the mandible. It is therefore essential to take extra care in submandibular approaches to the neck and the facial skeleton.

\section{Additional Information}

\section{Disclosures}

Human subjects: All authors have confirmed that this study did not involve human participants or tissue. Conflicts of interest: In compliance with the ICMJE uniform disclosure form, all authors declare the following: Payment/services info: All authors have declared that no financial support was received from any organization for the submitted work. Financial relationships: All authors have declared that they have no financial relationships at present or within the previous three years with any organizations that might have an interest in the submitted work. Other relationships: All authors have declared that there are no other relationships or activities that could appear to have influenced the submitted work.

\section{References}

1. Maitreyee M, Belsare S: Methods to learn human anatomy: perceptions of medical students in paraclinical and clinical phases regarding cadaver dissection and other learning methods. Int J Res Med Sci. 2016, 4:2536-41. Accessed: November 14, 2019: 10.18203/2320-6012.ijrms20161888

2. García Martín J, Dankloff Mora C, Aguado Henche S: Possibilities for the use of Anatomage (the anatomical real body-size table) for teaching and learning anatomy with the students. Biomed J Sci Tech Res. 2018, Accessed: November 14, 2019: 10.26717/BJSTR.2018.04.001094

3. Spitzer V, Ackerman MJ, Scherzinger AL, Whitlock D: The visible human male: a technical report . J Am Med Inform Assoc. 1996, 3:118-30. DOI:10.1136/jamia.1996.96236280

4. Ackerman MJ: The Visible Human Project: a resource for education . Acad Med. 1999, 74:667-70. 10.1097/00001888-199906000-00012

5. Park JS, Chung MS, Hwang SB, Shin BS, Park HS: Visible Korean Human: its techniques and applications . Clin Anat. 2006, 19:216-24. 10.1002/ca.20275 
6. Park JS, Chung MS, Hwang SB, Lee YS, Har DH, Park HS: Visible Korean Human: improved serially sectioned images of the entire body. IEEE Trans Med Imaging. 2005, 24:352-60. 10.1109/TMI.2004.842454

7. Kochhar A, Larian B, Azizzadeh B: Facial nerve and parotid gland anatomy. Otolaryngol Clin North Am. 2016, 49:273-84. 10.1016/j.otc.2015.10.002

8. Gray's Anatomy, 39th Edition. Standring S (ed): Churchill-Livingstone, Edinburgh; 2004. 10.1136/emj.2005.027847

9. Dingman RO, Grabb WC: Surgical anatomy of the mandibular ramus of the facial nerve based on the dissection of 100 facial halves. Plast Reconstr Surg Transplant Bull. 1962, 29:266-72. 10.1097/00006534196203000-00005

10. Batra APS, Mahajan A, Gupta K: Marginal mandibular branch of the facial nerve: an anatomical study . Indian J Plast Surg. 2010, 43:60-4. 10.4103/0970-0358.63968

11. Woltmann M, Faveri R, Sgrott EA: Anatomosurgical study of the marginal mandibular branch of the facial nerve for submandibular surgical approach. Braz Dent J. 2006, 17:71-4. 10.1590/s0103-64402006000100016

12. Saylam C, Ucerler H, Orhan M, Uckan A, Ozek C: Localization of the marginal mandibular branch of the facial nerve. J Craniofac Surg. 2007, 18:137-42. 10.1097/01.scs.0000246732.69224.7e

13. Rödel R, Lang J: Studies of the course of the marginal branch of the facial mandibular nerve (article in German). Laryngorhinootologie. 1996, 75:368-71. 10.1055/s-2007-997596

14. Hwang K, Huan F, Ki SH, Nam YS, Han SH: Location of the mandibular branch of the facial nerve according to the neck position. J Craniofac Surg. 2012, 23:1488-90. 10.1097/SCS.0b013e3182587d93

15. Wang TM, Lin CL, Kuo KJ, Shih C: Surgical anatomy of the mandibular ramus of the facial nerve in Chinese adults. Acta Anat (Basel). 1991, 142:126-31. 10.1159/000147176

16. Kim DI, Nam SH, Nam YS, Lee KS, Chung RH, Han SH: The marginal mandibular branch of the facial nerve in Koreans. Clin Anat. 2009, 22:207-14. 10.1002/ca.20739

17. Balagopal PG, George NA, Sebastian P: Anatomic variations of the marginal mandibular nerve . Indian J Surg Oncol. 2012, 3:8-11. 10.1007/s13193-011-0121-3

18. Hwang K: Surgical anatomy of the facial nerve relating to facial rejuvenation surgery . J Craniofac Surg. 2014, 25:1476-81. 10.1097/SCS.0000000000000577

19. Touré S, Vacher C, Bertrand JC: Anatomy of the marginal mandibular branch of the facial nerve (article in French). Rev Stomatol Chir Maxillofac. 2004, 105:149-52. 10.1016/s0035-1768(04)72294-9

20. Touré G, Tran de Fremicourt MK, Randriamanantena T, Vlavonou S, Priano V, Vacher C: Vascular and nerve relations of the marginal mandibular nerve of the face: anatomy and clinical relevance. Plast Reconstr Surg. 2019, 143:888-99. 10.1097/PRS.0000000000005360 